\title{
Analysis of the energy policy establishment: the case of East Asia
}

\author{
Sergei Popov *, Melentiev Energy Systems Institute of Siberian Branch of the Russian \\ Academy of Sciences, Irkutsk, Russia
}

\begin{abstract}
The energy infrastructure is a complex and evolving technical system, vital for the very existence of modern civilization. The example of Japan highlighted the main actors and considered the basic mechanisms of energy policy as an institution for the development of energy supply systems at the national and sub-national levels. The knowledge of such institution is important for monetizing Russia's energy resources, considering East Asia as leading energy import market. The article analyse energy policy formation on the example of Japan as economy with the most mature energy institutions among other East Asian economies, and implications to the prospective energy export from the Russian Federation.
\end{abstract}

\section{Introduction}

The East Asian economies almost completely depend on energy import, as shown at Fig.1, where the ranking of the world's net energy exporters is presented. Taking into account vast energy resource base in the Asian regions of Russia, and their proximity to the huge Pacific regional international market (RIM) the natural strategy should be to monetise Russian resources through extensive energy infrastructure development in Northeast Asia.

Learning from institutional leaders, analysing successful energy policy cases is important to avoid traps and faults, as well as to accommodate best practice at minimum cost. On top of that, better understanding of the driving forces and internal processes towards goals of energy infrastructure development should provide advantages in the buildup of one's own energy policy.

Terminology is important for understanding and elaborating common language, either in the multifaceted institutional framework, or at the very beginning of the endeavour to gain common understanding within multilateral frameworks. The word policy, being synonym to the word strategy, make important difference for energy researchers and energy practitioners, such as government executives and business investors.

Definition of the word policy is 1) a line of argument rationalizing the course of action of a government [1]; or 2) a course, or principle of action adopted or proposed by an organisation or individual [2] (where course is "a procedure adopted to deal with a situation" [3]). For the world strategy corresponding definitions are 1) an elaborate and systematic plan of action [4]; 2) a plan of action designed to achieve a long-term or overall aim [5].

\footnotetext{
* Corresponding author: popovsp@isem.irk.ru
} 


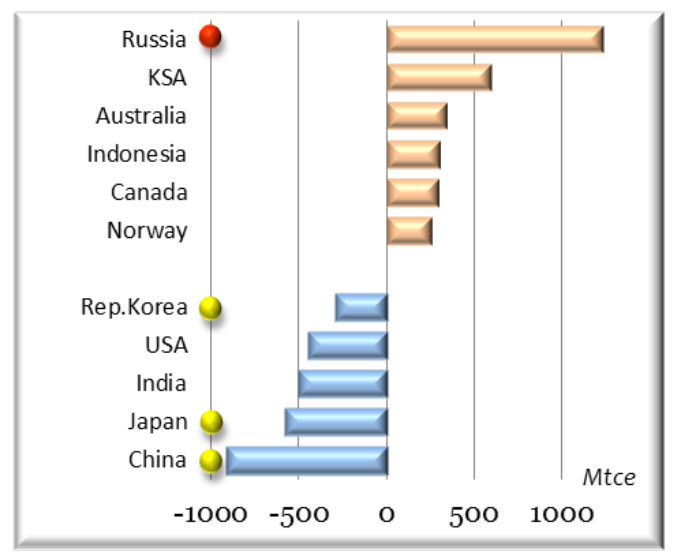

Fig. 1. Ranking of the top energy exporters and importers in 2016

In general, the term strategy refers to unique plan designed to reach the objectives set by the entity. It is an interpretative plan that guides the entity in realising its goal. On the other hand, policy refers to a set of rules for rational decision making. Policy lays down the course of action, which is opted to guide the entity's current and future decisions; one should know that policies are subordinate to strategy [6]. Here the terms goal, objective, and desire are appearing, which means that the foundation of the energy policy lies upon society's projections of the future shaped with preferences of some "better' options over "worse".

Every act of making a decision in the process of implementing energy policy is guided by a weighted sum of criteria. Ultimately, the ability of society to calculate such criteria under real current circumstances, the insightful diplomacy of political leaders, and the working mechanisms of implementation are keys to the success of [energy] policies, after having the right strategy.

However, further in this paper energy policy is considered rather as institutions and implementation mechanisms than the art of diplomacy.

\section{Why Japan?}

The East Asia region is critically important energy export market for the Russian Federation. While general structure of energy system is similar at any national and regional/local level, as shown at Fig. 2, the natural, social, economic, and political circumstances are playing important role in the process of the energy policy development. There are several of such important factors for the East Asia's economies:

- the strong dependence on energy import of almost all primary fuels, and highest concerns on energy security,

- the lack of an international infrastructure for the network transport of energy (power lines and pipelines),

- the attachment of energy prices to the price of oil,

- the increased competition in the gas market due to "shale evolution",,

- the low cost of sea transportation (in comparison to other modes) and in fact the island location of major energy consumption centres within the region (ideal for organising a global competitive market).

\footnotetext{
${ }^{l}$ Description of the "shale evolution" please see in the "Shale [r]Evolution" box
} 


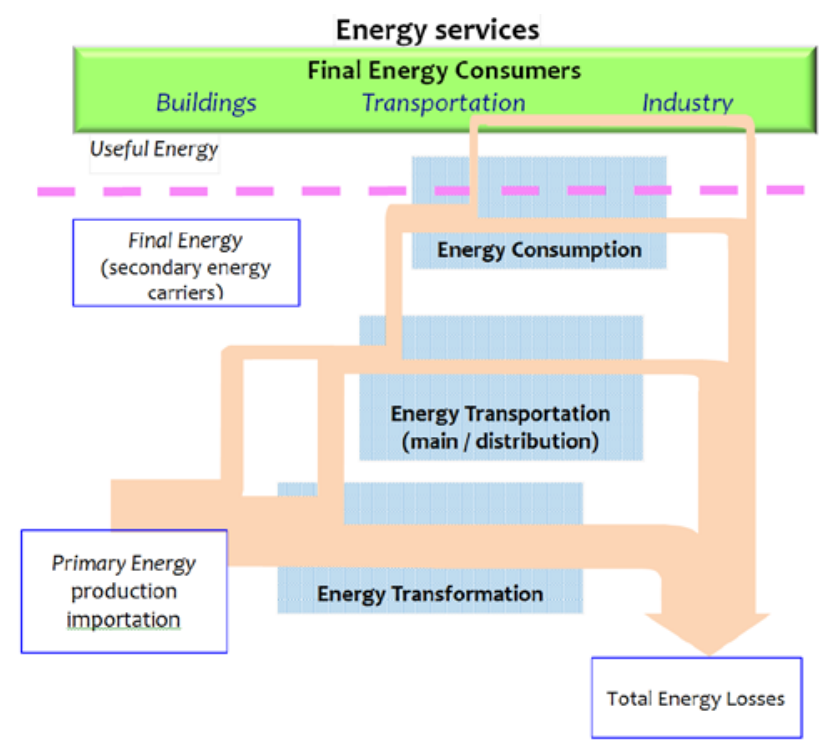

Fig. 2. The hierarchy of energy supply infrastructure

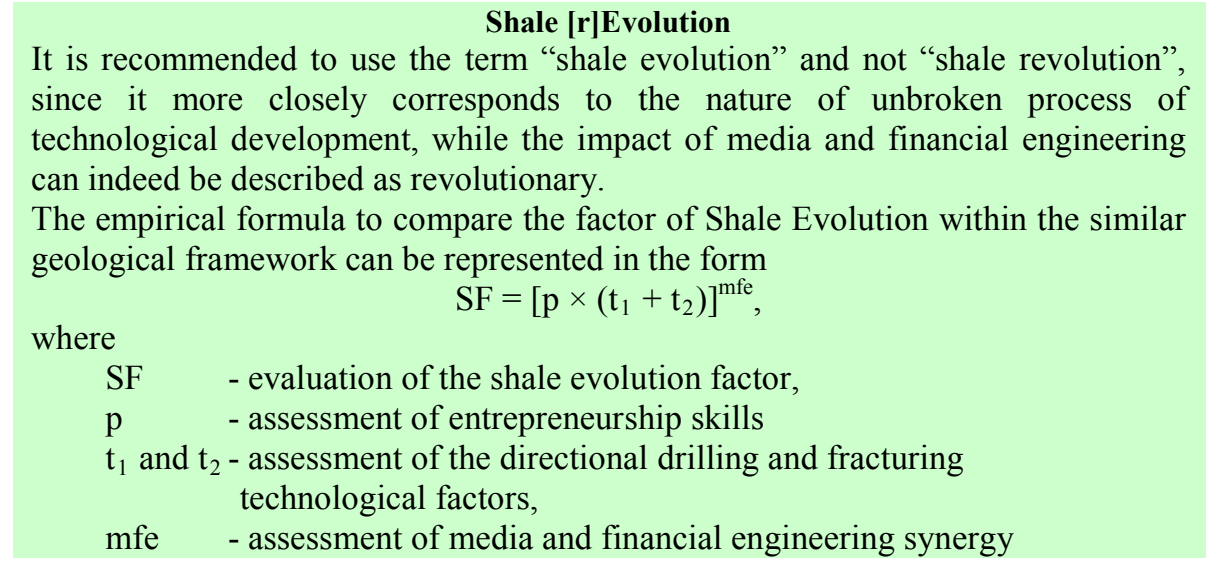

There are several reasons why Japan has been chosen as an object for the "energy policy" institutions' study:

- 150 years have passed since the Meiji revolution, the voluntary transition of the East Asian culture country to the path of industrialisation;

- the specifics of the Japanese society organisation and mentality seems to be characteristically within the East Asian region (in relation to the power division between the state, military and trade - such as Emperor, shogun, princes, and traders);

- the perfectionism in the working activity and susceptibility to innovation, combined with elite's prescription for leadership;

- the private business' dominance within the national economy;

- the most documented and open economy in East Asia for online researchers;

- other East Asian countries actively use the Japanese "pioneer" experience on their own pattern to modern industrial society.

Japan has made the bet on technology and entrepreneurship as the main drivers of its development. Such attitude allowed it to become the first among East Asian economies on the way to economic recovery after the Second World War. A few decades later, this choice 
has led to the fact that Japan ranked second in the world in terms of economic and technological status.

\section{Major Actors}

Considering the problems of energy policy, the central point is the issue of the participants within the process, otherwise called actors. It is possible to list several groups of such actors for industrialised economies:

- Central government (ministries, agencies);

- Large financial and industrial groups (corporate business);

- Government at the provincial level and municipalities

- Local industrial companies (business);

- Industrial and territorial business associations;

- Non-profit organisations concerned about energy-related issues;

- Research institutes/organisations involved in energy-related research or regulatory activity.

However, in order to simplify further analysis only two categories have been singled out - Government and Business. The former includes governments at various levels, as well as public institutions involved in energy infrastructure's development. The latter refers to any public activity related to meeting the society's needs for energy services, and making profit in a course of this activity.

In institutional studies, the next important point after identifying the composition of actors is the set of criteria that guide actors in decision-making process. The sets of such performance criteria and their grouping, inherent to the Government and Business, are fundamentally different. For Business there is essentially a single group of criteria related to profit. The Government is compelled to be guided by a number of criteria groups, each of which in turn is a fuzzy set of often conflicting criteria - both within and between of such criteria groups. Accordingly, actors in their practical activities (in a process of the energy policy implementation) are guided by procedures to elaborate multi-criteria optimum solution.

While the ownership structure within the energy sector varies greatly among East Asian economies, it seems that the gravity centre is shifting toward private capital, as shown at the Fig.3. If this trend is correctly identified, then Japan, ones more, is the leader of this process.

\begin{tabular}{|c|c|c|c|c|c|}
\hline \multirow[b]{2}{*}{ Industry } & \multicolumn{5}{|c|}{ Property } \\
\hline & & ate & & State & \\
\hline Power & Japan & & $\begin{array}{r}\text { China, } \\
\text { Mongolia }\end{array}$ & RoK, & $\begin{array}{l}\text { DPRK, } \\
\text { Taiwan }\end{array}$ \\
\hline Oil \& gas & Japan & & $\begin{array}{l}\text { China, } \\
\text { Taiwan, } \\
\text { RoK }\end{array}$ & Mongolia, & DPRK \\
\hline Coal & $\begin{array}{l}\text { RoK, } \\
\text { Mongolia }\end{array}$ & China & & DPR & \\
\hline
\end{tabular}

Fig. 3. The ownership structure within the energy sector in East Asia

In order to provide an example for Government and Business actors' criteria difference, to compare its structural complexity, the major and evident list of such criteria is presented as follows: 


\section{Profitability Set of Criteria}

- cost minimisation in the competitive market

- creation of new markets and new segments of existing market

\section{Government}

\section{Economic Set of Criteria}

- the cost of electricity reduction

- the economy's added value growth

- the cost of energy imports reduction

- the share of new, high-tech industries increase

Social Set of Criteria

- technology security improving

- environmental pollution reduction

- employee professional evolution

Political Set of Criteria

- the reliability of power supply improvement

- energy imports' dependence reduction

- energy imports' security improvement

- the mutual assistance system for energy supply in case of force majeure development

It is obvious that the set of criteria for assessing the decisions taken and the range of problems to be solved by the Government are much more diverse than those the Business is facing. After all, the Government is directly accountable to the entire population of the country and/or the region, while the business is only accountable to its owners and employees. As an illustration of the difference in the depth of problems at the national and regional level, the example of the social criterion of air pollution is considered. The concentration of the 2.5 micron particles in south-eastern Eurasia's as of January 18, 2018 is shown on Fig. 4. The mere fact of having this state of affairs gives rise to many unpleasant issues for the Government, while for Business it means either the opportunity to profit increase through non-accounting of external costs, or the emergence of new markets associated with the willingness of society to pay a higher price for the so-called "green" goods and services.

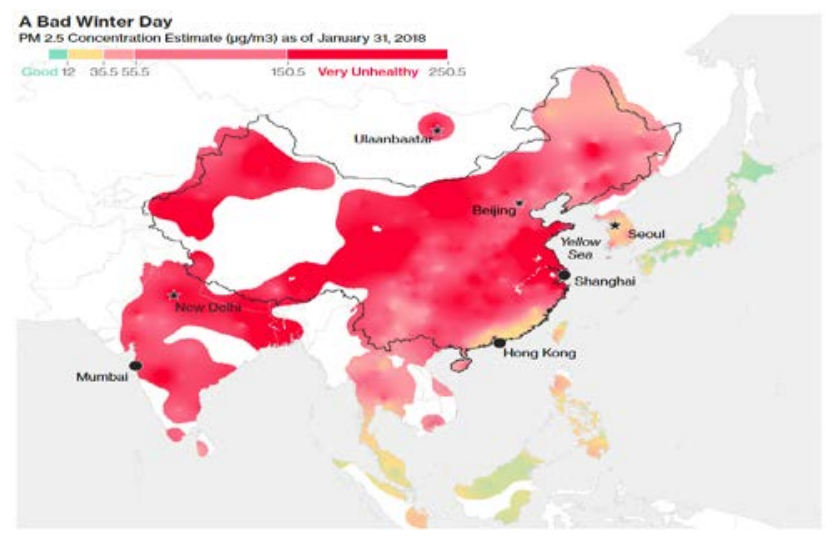

Fig. 4. Particles concentration in south-eastern Eurasia

The complexity of the efficiency criteria issues for the energy policy's evaluation in general, as a balance of society's costs and benefits, is illustrated by the antagonistic nature of such criteria for different actors. For the most commonly used economic group of criteria, the interests of Business and Government are opposite in many ways. For Business within perfect market institutions framework (when the government provides a competitive 
environment, and pricing mechanisms do not distort the real market's information/signals), the minimum cost is the main criteria for the investment decision's effectiveness. Under the framework of current national and international institutions, including energy security, the Government's main economic criterion for the success of its policy is the value added maximisation. The latter embrace aggregate activity of all Businesses categories in the real sector within the area of responsibility of the relevant Government's level. The intersection of the factors, influencing the search for compromises within the framework of energy policy institutions is indicated on Fig. 5.

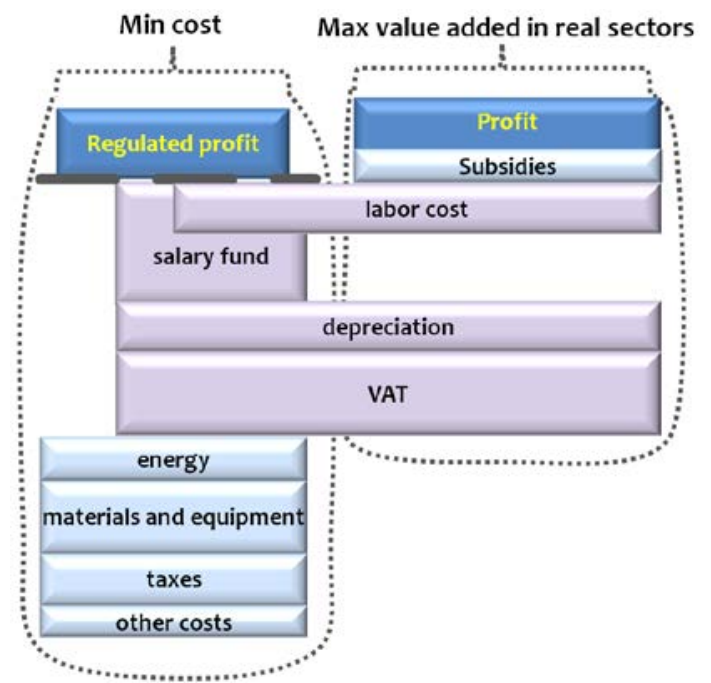

Fig. 5. Inconsistency within performance criteria for energy systems

\section{Energy Policy and Strategy}

\subsection{Implication of the oil price shock}

The growth in energy imports and the first economic shock because of rising oil prices in 1973 had a major impact on energy supply chain management institutions development in industrialised economies. In Japan both the Government and Business have become aware that in conditions of almost complete dependence on energy imports, including nuclear fuel, it is urgent to develop a coordinated long-term energy policy.

The political, financial and industrial authorities of Japan maidd a decision to use the factor of high energy prices as a driving force for the overall economic development and improvement of domestic industry's export competitiveness for consumer goods, industrial equipment and transport systems.

\subsection{The technological research organisation}

In 1974 the Japanese government initiated the so-called "sunshine" project, aimed at developing new energy supply technologies, later in 1978 supplemented by the "moonlight" project to develop innovative energy-saving technologies for energy consumers. Then, in October 1980, the New Energy Development Organisation (NEDO) was established with two major missions: addressing energy and global environmental problems, and enhancing industrial technologies [7]. NEDO is coordinating technology development efforts within 
the private sector. To become a leader in energy conservation, Japan made a significant investment. As an example, more than five trillion yen had been invested in over 25 years to improve energy efficiency of the steel industry's technological processes. This large scale, national-wide efforts were converted into numerous patented technologies, energyefficient and high-performance production equipment in almost all industrial branches, transport and construction equipment.

\subsection{The use of negative factors for the society's development}

The decline in Japanese coal production in the $1960^{\text {th }}$ and the need to ensure the growth of electricity production were used positively to boost the country's nuclear power development program. The miners who were laid off from underground and undersea coal mines became construction workers at nuclear power plants, and after nuclear power plant's commissioning - in the same place - turned into auxiliary personnel. Examples are numerous, from Sendai, where first unit of the Fukushima nuclear power plant (NPP) was commissioned in 1970, to Tomari nuclear power plant on Is. Hokkaido, where the country's last coal mine was closed in 2001. The depletion of local oil fields in Niigata prefecture and the concerted search by Governments and Businesses for new sources of economy's value added led to the construction of the world's largest nuclear power plant, KashiwazakiKariwa (total installed capacity is $8.1 \mathrm{GW}$ for seven units).

\subsection{Institute of public-private partnership (PPP)}

The Japanese government's control over the energy prices through the coordination of the profit rate with industry associations includes mechanisms for cost optimisation and business efficiency improvement. The presence of such a mechanism creates favourable conditions for the expansion and diversification of business through the search of new markets and new business opportunities establishment. Since these processes are mutually controlled both by the Government (representing provincial and central levels of the state's organisational structure) and Business (personalised by industrial and professional associations), the mutually verified costs of creating and developing new markets are taken into account when the rates of profit are controlling and coordinating.

Traditionally in the Japanese society, the private business initiative is approved by the government at all levels, but the latter reserves it's power to make a final decision. However, such ruling is taken after thorough and in-depth discussions with all stakeholders involved - ranged from business, groups of the population concerned, expert communities, and other similar non-commercial organisations.

\subsection{The PPP institute at the regional level}

The Japanese regional governments (as well as in most of the East Asian countries) are in the price-takers position on the world energy markets. At the same time, they should maintain the technological structure of energy supply infrastructure in such a way as to maximise the economy's value added within their jurisdiction. To establish a dialogue between the Government and Business the mechanism of demonstrational technology tests is used widely (in the range from local to international). The purposes of tests are to increase the level of confidence in technology, and to promote these technologies. In contract, the main instruments for regional authorities to control implementation of energy policy are subsidies (for consumers and energy suppliers), and permissions/licenses for energy investors. 


\subsection{Promotion of energy strategy and energy policy}

The energy strategy in Japan is binding. In case of Japan there is Strategic Energy Plan, which has to be revised at least every five years. The latest version of the Strategic Energy Plan includes Chapter 5, the last one, devoted to "communications with all levels of society on deepening of energy-related understanding". The Government is emphasising in the abovementioned law that these issue "matters essential to long-term, comprehensive and systematic implementation of measures related to energy supply and demand" [8].

The Japanese energy strategy is based on the principles of public-private partnership. Within this framework, the Government activities at the country, provincial and municipality levels are being coordinated with Business. Primary goal for such coordination is to stimulate technological development for segments of existing and emerging new energy markets. The important and integral part of the PPP is information sharing for population and capacity building for middle level business managers.

Clarity of energy goals and objectives, their visibility and openness are important practice to promote energy policy in Japan. Energy policy goals are characteristic feature of the capacity building and information sharing efforts. In the core of such social propaganda are both qualitative guidelines for the development of energy technologies, and quantitative characteristics for energy infrastructure targets. The latter, for example, includes expected average electricity price, corresponding to the price assumptions for the world energy markets. Another mechanisms are quite familiar for the so-called "planned economies", including initiatives both at national and regional level. The most important is approach to establish hydrogen energy infrastructure for environmentally neutral road transportation system in Tokyo, timed with the start of the 2020 Olympic Games.

\subsection{Mutual responsibility}

The experience of Japan confirms the fact that it is impossible to achieve success only through Government levers, without active voluntary participation of Business. The energy infrastructure development plans and strategies are jointly developing by the Government and Business. The slogans of energy policy are directed at innovative development in industries and economy sectors, in efforts to improve competitiveness of products and services produced in Japan, to increase expertise, competence, and experience for industrial and research personnel.

\subsection{Energy strategy of Japan 3E+S}

Japanese long-term energy strategy has its own established motto - " $3 \mathrm{E}+\mathrm{S}$ ", which means Energy, Economy, Environment (in any order preferred) under inherent requirements for Safety. The evidence from the Working Group on the electricity cost reexamination elaborates a bit on these items [9]. "Japanese style" is to unite efforts of the whole country to achieve the desired goal, which is set by the Government. This practice (bringing together various stakeholders) has become the core of Japan's institutions to develop energy strategy. As a result of intensive policy discussions, specific goals were formulated for the current version of the Japanese energy strategy. Considering the principle of energy system's safety as an imperative, they include:

- increase energy self-sufficiency level from 6 per cent to 25 per cent by year 2030,

- reduce electricity price to the level below that recorded in the beginning of year 2015 ,

- target level for GHG emissions must comply with goals adopted by leading economies. 


\subsection{Outlook (Forecasts, Projections)}

The common practice of today for energy infrastructure development is constructing the basic, or reference, or the most feasible scenario - "Business as Usual", BAU. Every stockholder is interesting in discussion with respect to this scenario, to provide its proposals for energy infrastructure's development. They may include accelerated abandonment of fossil fuels; reduction of greenhouse gas emissions; achievement of "energy independence"; enforcement utilisation of new technologies ("innovative scenario"), etc. Recently, such new energy paradigm has been nicknamed as "Energy Transition".

The Institute of Energy Economics, Japan (IEEJ) holds world-class competence in the area of energy economics analysis and energy demand and supply outlook, one of the most authoritative organisation within the East Asian region. Their Annual energy outlook for the World and Asia includes Reference (RS) and Advanced Technology (ATS) Scenarios. Key projection parameters for two major energy consumers in the East Asia region - China and Japan - are presented in Fig. 6 and Fig. 7. First, total primary energy demand under the RS and ATS is provided for each country, followed by difference between RS and ATS for year 2050 in relative and structural modes. The recent Outlook [10] suggests similar energy trends for Japan and China, thus confirms the thesis on leading role of Japan's energy institutions for energy policy formation in East Asia.

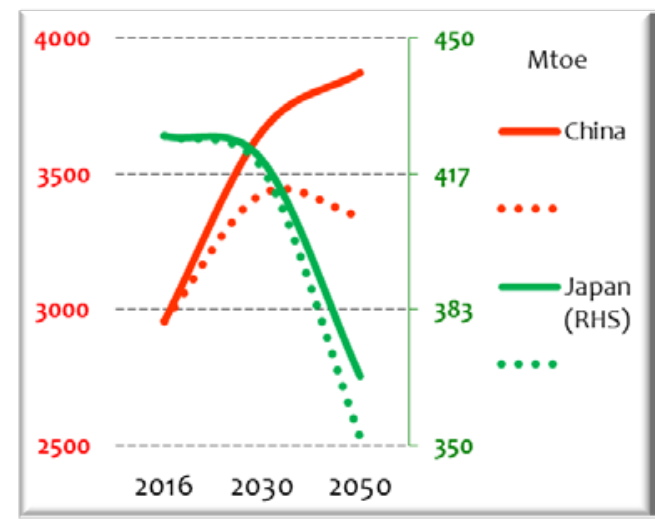

Fig. 6. Primary energy demand for China and Japan in RS and ATS, Mtoe

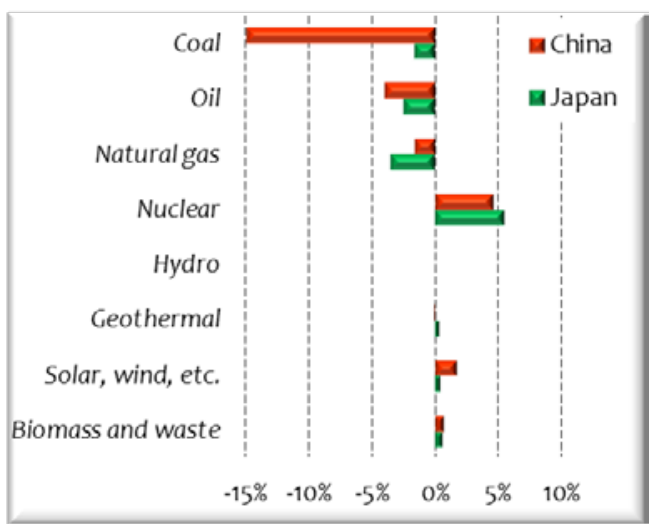

Fig. 7. Relative difference for primary energy demand for China and Japan in ATS and RS for year 2050, per cent. 


\section{Energy Import Assessments for East Asia}

The International Research centre "Energy infrastructure in Asia" is participating actively in studies on current and future international energy activity within East Asia region. Its methodological Toolbox includes [11]:

- Information base on energy consumption, macroeconomic data, and institutions.

- Set of models to provide in-depth analysis and make estimations for future development patterns of the energy supply chain (from primary energy production to energy service provided) at different levels - from regional energy infrastructure objects (final energy demand by types of consumers, elements of domestic energy infrastructure and energy production/transformation), to international energy trade/transportation infrastructure.

- Research methodology, which incorporate technological, economical, and institutional factors into complex procedures to produce energy import assessments.

The database include energy and macroeconomic statistics for China, Japan, Republic of Korea, Democratic People's Republic of Korea, Mongolia, Taiwan province of China at national level, and has additional Energy Balance Table at provincial level for China. On the base of proprietary forecasting methodology, utilising analysis of energy outlooks from world-leading institutions like IEA, EIA and IEEJ, we provide our own vision for credible energy development pattern for each East Asian economy. The table 1 presents author's estimations for the East Asia's import balance in years 2030 and 2050.

Table 1. East Asia's Energy Import Assessments

\begin{tabular}{|l|c|c|c|}
\hline \multirow{2}{*}{ Year } & coal & crude oil & natural gas \\
\cline { 2 - 4 } & $\mathrm{Mt}$ & $\mathrm{Mt}$ & $\mathrm{BCM}$ \\
\hline 2016 (history) & 621 & 731 & 245 \\
\hline 2030 & $600-630$ & $800-850$ & $440-480$ \\
\hline 2050 & $560-600$ & $880-960$ & $510-580$ \\
\hline
\end{tabular}

\section{Findings and implications}

- One of the most developed capitalist countries has successfully built a stable system for strategic energy planning.

- Cooperation between authorities and business on regional level plays an important role in Japanese energy planning institutions; it is important both for R\&D process, and for the process of the country's energy policy implementation.

- The Republic of Korea and Taiwan, accompanied partly by China, use the experience of Japan as a leading economy on the world's energy markets, and essentially strengthen the single market of energy importers within the East Asia region.

- The goal for energy sector development is to create favourable opportunities for other economy's real sectors utilising technological factors, including formation of new markets.

- A start for new phase of energy transition to renewable energy was benchmarked by Japan: the national-wide development of hydrogen energy infrastructure.

- The traditional energy markets will enter in to more competitive environment with steady demand growth for renewable energy.

\section{Acknowledgment}

Preparation and publication of this article was supported by the project AAAA-A17117030310434-3 of the Russian Academy of Sciences. 


\section{References}

1. Policy, Webster's 1913 Dictionary; http://www.websterdictionary.org/definition/policy. - access date: 09.06.2018

2. Main definitions of policy in English; https://en.oxforddictionaries.com/definition/policy. - access date: 09.06.2018

3. Definition of course in English; https://en.oxforddictionaries.com/definition/course. access date: 09.06.2018

4. Strategy, Webster's $1913 \quad$ Dictionary; http://www.websterdictionary.org/definition/strategy. - access date: 09.06.2018

5. Definition of strategy in English; https://en.oxforddictionaries.com/definition/strategy. - access date: 09.06.2018

6. Difference Between Strategy and Policy; https://keydifferences.com/differencebetween-strategy-and-policy.html. - access date: 09.06.2018

7. About NEDO; http://www.nedo.go.jp/english/introducing_index.html. - 21.12.2016. access date: 12.06 .2018

8. Strategic Energy Plan, Provisional Translation;

http://www.enecho.meti.go.jp/en/category/others/basic_plan/pdf/4th_strategic_energy_ plan.pdf. - April 2014. - access date: 09.06.2018

9. Inside Japan's Long-term Energy Policy; http://eneken.ieej.or.jp/en/report_detail.php ?article_info_ id $=6291 .-18.09 .2015 .-$ access date: 18.05 .2018

10. IEEJ Outlook 2019 - Energy transition and a thorny path for 3E challenges - Energy, Environment and Economy/Report; http://eneken.ieej.or.jp/data/8122.pdf. 15.10.2018. - access date:19.10.2018

11. Popov S.P., Metodicheskyi podkhod $\mathrm{k}$ ozenke potrebnosti $\mathrm{v}$ rossiiskykh energoresursakh na rynkakh Vostochnoi Azii //Sed'mye Melentievskiye chtenia, ed. Makarov A.A., - Moscow, ERI RAS, pp. 116- 127 (2013) (in Russian) 